\title{
Adherence to Hip Protectors and Implications for U.S. Long-Term Care Settings
}

\author{
Sheryl Zimmerman, PhD*, Jay Magaziner, $\mathrm{PhD}^{\dagger}$, Stanley J. Birge, MD ${ }^{\ddagger}$, Bruce A. Barton, \\ PhD§, Shari S. Kronsberg, MS§, and Douglas P. Kiel, MD, MPH \\ *Program on Aging, Disability and Long-Term Care, Cecil G. Sheps Center for Health Services \\ Research, and the School of Social Work, University of North Carolina at Chapel Hill, Chapel Hill, \\ NC \\ †Division of Gerontology, Department of Epidemiology and Preventive Medicine, University of \\ Maryland Baltimore, Baltimore, MD \\ ¥Division of Geriatrics and Nutritional Science, Washington University School of Medicine, St. Louis, \\ $\mathrm{MO}$ \\ \$Maryland Medical Research Institute, Baltimore, MD \\ "Hebrew Senior Life Institute for Aging Research and Harvard Medical School, Boston, MA
}

\begin{abstract}
Objectives: Determine nursing home characteristics related to adherence to use of a hip protector (HP) to prevent fracture; also describe adherence and related resident characteristics.

Design: A multi-center, randomized controlled trial of a HP in which adherence to wearing the HP was monitored by research staff three times a week for up to 21 months; data were collected by interviews and chart review.
\end{abstract}

Setting: Thirty-five nursing homes in Boston, St. Louis, and Baltimore.

Participants: A total of 797 eligible residents, 633 (79\%) of whom passed the run-in period, 397 (63\%) of whom remained in the study until the end of follow-up.

Intervention: Residents wore a single HP on their right or left side.

Measurements: In addition to regular monitoring of adherence, data were collected regarding facility characteristics, staffing, policies and procedures, perception of HPs and related experience, and research staff ratings of environmental and overall quality; and also resident demographic characteristics, and function, health, and psychosocial status.

\footnotetext{
(C) 2009 American Medical Directors Association. Published by Elsevier Inc. All rights reserved.

Corresponding Author: Sheryl Zimmerman, PhD University of North Carolina at Chapel Hill Cecil G. Sheps Center for Health Services Research 725 Martin Luther King Jr. Boulevard Chapel Hill, NC 27590-7599 Telephone: 919-962-6417; Fax: 919-966-1634 Sheryl_Zimmerman@unc.edu. Alternate Corresponding Author: Douglas P. Kiel, MD, MPH Hebrew Senior Life Institute for Aging Research 1200 Centre Street Boston, MA 02131 Telephone : 617-363-8544 ; Fax : 617-363-8936 kiel@ mail.hrca.harvard.edu.

Publisher's Disclaimer: This is a PDF file of an unedited manuscript that has been accepted for publication. As a service to our customers we are providing this early version of the manuscript. The manuscript will undergo copyediting, typesetting, and review of the resulting proof before it is published in its final citable form. Please note that during the production process errors may be discovered which could affect the content, and all legal disclaimers that apply to the journal pertain.

Conflict of Interest: The authors have no financial or personal conflicts of interest related to the work reported in this manuscript.
} 
Results: Facility characteristics related to more adherence were not being chain-affiliated; less Medicaid case-mix; fewer residents wearing HPs; more paraprofessional staff training; more rotating workers; and having administrators who were less involved in meetings.

Conclusion: Efforts to increase adherence to the use of HPs should focus on facilities with more Medicaid case-mix to reduce disparities in care, and those that have less of a culture of training. Staff may need support to increase adherence, and when adherence cannot be maintained, HP use should be targeted to those who remain adherent.

\section{Keywords}

hip fracture; nursing homes; compliance

\section{INTRODUCTION}

More than 340,000 hip fractures occur in the U.S. each year.1 These fractures typically follow a fall, and result in excess dependency and mortality. $2^{, 3}$ Their concern is especially notable in nursing homes (NHs), where $97 \%$ of residents have osteoporosis or osteopenia and their rate of hip fracture is 3-11 times that of age-matched community dwellers. ${ }^{4-} 6$

Non-pharmacologic treatments such as hip protectors (HPs) are attractive options to reduce fractures as they avoid the expense and side-effects of medications and their effect is immediate. They are typically composed of a hard shell or dense foam, and fit into an undergarment that positions the HP over the trochanteric prominence. Depending on their style, HPs either absorb (foam) or divert (shell) the energy of a fall away from the greater trochanter to the soft tissue around the hip. Initial evidence regarding the efficacy of HPs was promising, although recent reviews and studies are equivocal; still, newer materials may prove effective in reducing fractures. ${ }^{7-9}$

One problem has plagued virtually all studies of HPs: low adherence. A recent review found adherence between $20-92 \%$ (median 56\%), with reasons for non-use related to comfort, effort, incontinence, and physical difficulties. ${ }^{10}$ It is challenging to compare results across studies because some ask perceptions rather than use; 11 some rely on focus groups; 12 eligibility criteria and length of follow-up differ; and adherence is assessed using different respondents, timeframes, and strategies.9,13-18 Of note, only two of the latter studies were based in the U.S. and focused on a $\mathrm{NH}$ population, and both included only one $\mathrm{NH}$ each. ${ }^{17,18}$

In the U.S., 15,294 NHs with 1.6 million beds cared for 1.4 million residents in 2006. ${ }^{19-21}$ While information regarding characteristics related to HP adherence from single site studies is informative, it cannot inform facility-level characteristics that relate to adherence - many of which may be modifiable. The importance of facility-level characteristics is evident in other studies that found a relationship between resident outcomes and facility characteristics including ownership, affiliation, case-mix, staffing, services, administrative priorities, and family involvement. ${ }^{22-23}$

This study examined HP adherence in a large number of U.S. NHs and examined the facilitylevel predictors of adherence in a randomized trial. Further, it assessed resident-level characteristics related to adherence and delineated and compared residents who did and did not wear HPs at all, an area that has received less attention but is important if these devices are to have an effect on hip fracture incidence. The data derive from the Hip Impact Protection Project (HIP PRO), a randomized controlled clinical trial conducted by three clinical centers (Hebrew Rehabilitation Center, Boston, MA; University of Maryland, Baltimore, MD; Washington University, St Louis, MO) and a data coordinating center (Maryland Medical 
Research Institute, Baltimore, MD). Results of these analyses suggest how facility organization and leadership can increase adherence to HPs.

\section{METHODS}

\section{Randomization, Eligibility, and Recruitment}

HIP PRO corrected methodological limitations of other studies that randomized by facilities or by residents; instead, it randomized at the level of the hip, such that each resident had one protected and one non-protected hip. The administrators of eligible NHs agreed to this randomization, and the $\mathrm{NH}$ had to have at least 100 beds and be in proximity to a clinical center. Each NH was randomly selected to be a "right" or "left" sided facility, and all residents in that setting wore the HP on the same side. Doing so was assured by undergarments that had only one pocket to house the HP and which were clearly labeled to differentiate front from back. The first facility was enrolled October 2002 and data for these analyses were collected through October 2004.

Residents were eligible if they were 65 years of age or older; were long-stay; at least attempted to get out of the bed or chair or walk without human assistance in the past four weeks; and did not have a history of bilateral hip fractures or hip replacement surgery, a contagious disease necessitating isolation, pressure ulcers, blisters or skin tears over bony prominences that would be covered by the HP garment, hip circumference $\geq 49$ inches, or staff recommendation not to enroll because of behaviors affecting adherence (e.g., not willing to wear undergarments). Power estimates to determine the efficacy of the HPs indicated a need to follow 546 residents. To obtain this number, residents who died, withdrew, or became ineligible (e.g., bedbound) were replaced. For these analyses, data from only those residents who were enrolled in the first nine months in each facility were used, to assure that the potential facility-level predictors collected at facility enrollment were timely.

Able residents provided their own consent and a responsible party provided consent for others while they provided assent. All residents participated in a two-week run-in trial to exclude those with poor adherence. During this time, research staff made six unannounced visits. If a resident was wearing the HP incorrectly at more than two visits, he/she was withdrawn.

However, if the reason for non-adherence was staff or HP problems (e.g., no clean garments), an additional two-week run-in period was permitted after the problem was corrected.

All procedures were approved by the Institutional Review Boards of the Clinical Centers and the Coordinating Center. Further details about the design can be found elsewhere. ${ }^{8,24}$

\section{Measures}

Data included those related to adherence and characteristics of facilities and residents that were examined in other studies of HP adherence and $\mathrm{NH}$ outcomes.

Adherence-Adherence was determined by research staff observation. Residents were visited unannounced by research staff three times per week across all shifts and days of the week. If the protector was not being worn or not being worn correctly, the resident was considered non-adherent. Depending upon when they were enrolled, residents were observed for adherence for between 1-21 months (mean 11.0, S.D. 6.1).

Facility characteristics-Data related to facility characteristics were obtained from interviews with the administrator, director of nursing (DON), and research staff. Information related to demographic characteristics (bedsize, years in operation, proprietary status, chain affiliation, and case-mix); staffing (administrator and DON years in the facility; use of 
universal, specialized, and rotating workers who work on more than one unit; staffing ratio, vacancy, turnover and temporary staffing of the DON, registered/licensed nurses, and certified nursing assistant positions; and an overall nurse staffing ratio); policies and procedures, and their perception of hip protectors and related experience. In reference to policies and procedures, organizational leadership was related to administrator and DON attendance in meetings with professional and non-professional staff and the director of physical therapy; it combined Likert scales to create an overall meeting frequency ranging from 3-12.

Administrative priorities for the administrator and DON were obtained by reviewing the rank ordering of 12 activities used in prior work. ${ }^{23}$ Those that were ranked most important by at $\geq$ $25 \%$ of respondents included "treating residents respectfully" and "being aware of resident's medical status". For each respondent, the twelve rankings were collapsed into three categories, and analyses examined whether respect and medical status awareness were ranked among those of highest priority (top four items), middle priority (next four items), or lower priority (last four items). The final policy and procedure items related to the number of and participation in in-service trainings in the last quarter and whether or not a falls prevention program was in place. ${ }^{23}$ Perception of hip protectors related to the administrator's and DON's perceptions regarding the extent to which protectors prevent fractures and how residents feel about wearing protectors, with a summative score of 0-4. The percent of residents enrolled in the trial (overall and of those eligible) was calculated as a measure of the intensity of facility exposure. Administrators and DONs also reported on related experience in the context of previous research involvement in the past year. Finally, research staff evaluated environmental quality using the Therapeutic Environment Screening Survey ${ }^{25}$ which creates a scale ranging from 12-38. Research staff also reported on facility commitment to protector use based upon whether mechanisms were in place to assure adherence such as consequences for lack of use, staff commitment to protector use (scored 1-4), quality of interaction between research and facility staff (scored 1-4), the general working environment (scored 1-5), and the quality of care (the mean of seven items [alpha 0.93] scored 1-5 that assess to what extent the administrator and DON have respect from the staff, the staffing ratio, the frequency of toileting, the response time to residents' requests, the quality of communication between staff and residents, and overall staff morale).

Resident characteristics-Chart data provided information about demographic characteristics (age, gender, race, marital status and education); functional status (behavioral symptoms including verbally abusive, physically abusive, socially inappropriate/disruptive, and resistant to care; wandering; depressed, sad or anxious mood; continence of bladder and bowel; mobility; and history of falls; and health status (osteoporosis, dementia, and depression diagnosis, history of hip fracture, number of medications, medications for osteoporosis, and body mass index). Data also were obtained from interviews with residents regarding cognitive function using the Short Blessed Test (with a score $\geq 12$ indicative of cognitive impairment, which corresponds to a score of 19 on the Mini Mental Status Examination); ${ }^{26}$ and regarding psychosocial characteristics with an eight item fear of falling measure27 (scored 1-5), and a measure of perceived need for and benefit of the HP (scored 1-4). The care provider who knew the resident best reported on the family's frequency of visits. In addition, research staff reported on each resident's body image shape by selecting one of nine images modified from a National Heart, Lung, and Blood Institute study; ${ }^{28}$ these ratings correlated $0.72(\mathrm{p}<.001)$ with resident ratings, and because there were less missing data from research staff, their data were used in analyses.

\section{Statistical Methods}

Descriptive statistics included means, standard deviations, and percentages for categorical variables. Monthly percent adherence, used as the outcome in the models described below, was calculated for each resident as the number of research staff visits on which the resident was 
wearing the HP correctly, divided by the total number of visits for the month, with the resulting proportion multiplied by 100 .

To select variables for the multivariate models, each facility- and resident-level characteristic was included in a model with only that variable as the predictor of adherence. Variables that were significantly related to adherence $(\mathrm{p}<0.05)$ were included in multivariate models. Multivariate models were constructed by including all significant variables from the bivariate models in the full, initial model and stepping non-significant $(\geq 0.05)$ variables out one at a time in a downward fashion. No interactions were tested. Initial models were constructed with related variables (such as demographic characteristics) included in a model. Significant variables from those models then were included in a combined model in which all significant variables from all conceptual areas (e.g., demographic characteristics, staffing, policies and procedures, hip protectors and related experience, research staff ratings) were included. Pvalues less than 0.05 are considered to be significant in these models. Since this is an exploratory analysis, no adjustment for multiplicity of testing was made. All models were tested using mixed model methodology ${ }^{29}$ because of the inherent correlation with observations (resident months) and the inherent correlation within NHs. This is especially true when including both facility- and resident-level characteristics in the models. All analyses were performed using SAS (SAS Institute, Inc., Cary, NC).

\section{RESULTS}

Of the 35 NHs participating in this project, almost one-half were for profit (46\%), and not chain-affiliated (53\%); their average bed size was 182 (SD 120). A total of $7152 \mathrm{NH}$ residents were screened for participation. Of these, 3816 (53\%) were not eligible, the majority because they never attempted to stand up ( $\mathrm{n}=1909)$. Of the 3336 who were eligible, 68\% $(\mathrm{n}=2268)$ refused to participate, and another 26 did not enter the run-in period for reasons such as subsequent ineligibility or death. The remaining 1042 residents entered the run-in, 797 of whom entered the study within the first nine months of facility enrollment. Of these, $164(20 \%)$ did not pass the run-in, $236(30 \%)$ passed the run-in but later dropped out, and $397(50 \%)$ remained in study until follow-up data collection was completed.

Comparisons of those who refused to participate, did not pass the run-in, and subsequently dropped out provide information on the characteristics of residents willing to wear HPs. Those who agreed to participate versus those who refused did not differ in terms of age, gender, race, or ethnicity. Those who did or did not pass the trial did not differ in terms of behavior or depression, but those who did not pass were significantly more likely to be continent; mobile; not to have fallen in the preceding six months; and less likely to have a dementia diagnosis or be taking osteoporosis medicines.

\section{Adherence}

In total, 13,293 adherence observations were made of 633 subjects over 21 months. Figure 1 illustrates adherence by resident time in study (Figure 1a), and among NHs by NH time in study (Figure 1b). Figure 1a indicates that during each resident's first month of protector use, adherence averaged $81 \%$ (interquartile range $70-93 \%$ ). Mean adherence remained at $75 \%$ or more, although the interquartile range was wider and extreme values lower after the residents' first month of participation. Across all months, adherence averaged 76\% (range 0-100\%; interquartile range 64-100\%). Adherence in NHs by their own time in the study (Figure 1b) ranged between $0-100 \%$, with an average of $78 \%$ (interquartile range $65-86 \%$ ) and no significant change over time. Of note, the months in these figures cannot be compared, because, for example, a resident's first month in the study may not correspond to a facility's first month in the study due to rolling recruitment. 


\section{Relationship of facility characteristics to adherence}

Multivariate analyses comparing facility characteristics to adherence (see Table 2) found significant associations between the following variables and more adherence $(\mathrm{p}<.05)$ : demographic characteristics of larger bed size, nonprofit status (i.e., adherence in non-profit facilities was $5.65 \%$ higher than in for-profit facilities), having fewer Medicaid residents, and not being affiliated with a chain (i.e., adherence was 5.8\% higher in non-affiliated facilities); staffing characteristics of more use of rotating workers, a lower staffing ratio of professional nurses and paraprofessionals to number of residents, and more DON experience; policies and procedures including less organizational leadership (involvement in meetings with others), the DON prioritizing the need to treat residents respectfully (i.e., adherence was more than 15\% higher compared to when respect was considered as least important), and a higher percent of nonprofessional staff attending in-service training; hip protector and related experience including fewer eligible residents enrolled and a history of both the administrator and DON being involved in research as opposed to only the DON; and research staff ratings of better environment quality, more $\mathrm{RN}$ commitment to protector use, better quality of interaction between the research and facility staff, and better quality of care.

The final section of Table 2 provides the data for variables that remained significantly related to adherence when all significant demographic characteristics, staffing characteristics, policies and procedures characteristics, HP and related experience characteristics, and research staff ratings were entered into a multivariate model. Facility characteristics related to more adherence included proportionately fewer residents on Medicaid, not being chain-affiliated (related to $6.73 \%$ more adherence), having more rotating workers, less administrator involvement in meetings, the DON prioritizing respect for resident (related to 7.44-8.13\% more adherence), more in-service training attended by nonprofessionals, and fewer eligible residents enrolled in HIP PRO.

\section{Relationship of resident characteristics to adherence}

Multivariate analyses comparing resident characteristics to adherence (Table 3) found significant associations between the following variables and more adherence $(\mathrm{p}<.05)$ : demographic characteristics of white race and being married; functional status characteristics of no cognitive impairment, wandering, no consistent depression, bladder incontinence, bowel continence, and not being in a wheelchair; and health status characteristics of having an osteoporosis diagnosis.

The final section of Table 3 provides the data for the variables that remained significantly related to adherence when all significant demographic characteristics, functional status characteristics, and health status characteristics were entered into the multivariate model. Characteristics associated with more adherence include white race (related to $8.76 \%$ more adherence), no cognitive impairment (6.63\% more adherence), daily wandering (5.09\%), no consistent depression (5.4\%), occasional bladder incontinence (5.44\%), bowel continence, not being in a wheelchair (7.08\%), and having an osteoporosis diagnosis $(4.78 \%)$.

\section{Relationship of facility and resident characteristics to adherence}

Table 4 provides the data for the variables that remained significantly related to adherence when those from the combined facility and combined resident models were included in one multivariate analysis. Characteristics related to more adherence were fewer residents on Medicaid, not being chain-affiliated, have proportionately more rotating workers, less administrator involvement in meetings, more in-service training attended by nonprofessionals, and fewer eligible residents enrolled in HIP PRO; and residents who were cognitively intact, wandered on a daily basis, were not consistently depressed, had occasional bowel incontinence, and were not in a wheelchair. 


\section{DISCUSSION}

This, the largest study of its type in the U.S., is the first to broadly examine the relationship of $\mathrm{NH}$ characteristics to HP adherence. It is of importance because it can help explain rates of adherence ranging from $20-92 \%,{ }^{10}$ and provide guidance for organizational change to promote HP use. The final analytic model that combined significant facility- and resident-level characteristics identified six facility characteristics related to more adherence. One unfortunate finding is that adherence was lower in facilities with a higher Medicaid case-mix. This finding is consistent with reports of fewer resources and more health-related deficiencies in NHs with more Medicaid residents. ${ }^{30}$ Facilities with higher Medicaid case-mix also are more likely to serve African American residents, which may explain why this resident-level variable became non-significant in the combined model. Thus, it is possible that racial and socioeconomic disparities in adherence are less related to resident-level characteristics than to health system factors, and this is the first study to document the extension of that disparity to the use of HPs.

Not surprisingly, more paraprofessional training related to adherence, and NHs that better prepare staff for their work, in general, are likely to evidence higher adherence. Other studies also have demonstrated the positive effect of training on falls and hip fracture prevention.31, 32 This study also found that having more rotating workers is related to more adherence. As such, it is the third study to run counter to prevailing wisdom in suggesting that permanent (non-rotating) staffing is not always beneficial to residents.33,34 In the case of adherence to HPs, it may be that new staff are especially vigilant to resident care plans due to their unfamiliarity with the resident. While the conclusions do not necessarily suggest the use of rotating workers, they do suggest that NHs focus on more frequent review of and attention to care plans. These two findings, related to training and diligence to care plans, may explain in part why adherence was higher in facilities in which administrators were less involved in meetings; that is, it may be that administrators are less involved when other procedures are in place to assure quality care. In support of this conclusion, administrators were less involved in meetings in NHs that had a falls prevention program (Pearsons $r=-.39$ ), commitment to HPs $(\mathrm{r}=-.37$ to -.54$)$, and better quality of care $(\mathrm{r}=-.63)$, and more involved in settings that evidenced more DON and RN staff turnover $(r=.48$ and .38$)$. This interpretation provides hypotheses for further study.

The more eligible residents who were wearing HPs, the less the adherence. This finding persisted when resident-level characteristics were added to the model, suggesting it was the sheer number of residents, rather than their dependence, that related to adherence. One interpretation of this finding relates to the time required for staff to dress residents in the HP. Given the amount of care required by NH residents, the workforce shortages, ${ }^{35}$ and that overburdened staff relegate optional tasks to a secondary status, ${ }^{36}$ these findings suggest three avenues of action. The first is to bolster the workforce, such as to involve families in promoting HP use. Indeed, family involvement is related to increased adherence. ${ }^{18}$ The second is to provide staff education about the risks and consequences of hip fracture. The third is to target the use of HPs to those most in need, and emphasize their use as an integral component of the care plan.

Finally, non-profit ownership and not being affiliated with a chain were related to almost $6 \%$ more adherence. There is abundant evidence that for-profit status is related to poorer quality care and outcomes ${ }^{23,37}$ and that the majority of for-profit $\mathrm{NHs}$ are affiliated with a chain while only a minority of non-profit $\mathrm{NHs}$ have a chain affiliation. ${ }^{38}$ Thus, findings from the current study add to what has been written about for-profit NHs by extending it to adherence with care practices. 
This study also demonstrated that with careful attention to adherence, rates averaging $75 \%$ or more can be sustained for as long as two years. This figure is markedly higher than other studies (e.g., Kurrle obtained 53\% adherence). ${ }^{13}$ Of course, this study used a run-in period which excluded those with poor adherence; also, as an efficacy study, neither this study nor others can assure that the observed adherence rates will be achieved in daily practice. On the other hand, being a research project and not a standard of care may have adversely affected adherence. It is in this context that this study provides guidance as to the types of facilities in which special efforts will be necessary to maximize the use of HPs - NHs that have a higher Medicaid and African American case-mix, less of a culture of staff training, and staff who are more burdened and may not be able to attend as closely as desired to resident care plans. In instances when staff cannot attend closely to all residents who might benefit from HPs, it is suggested that their use be targeted to those residents who are most likely to use them.10,18

Residents who passed the two-week run-in period were significantly more likely to be incontinent and not independently mobile; to have fallen in the preceding six months; and to have a dementia diagnosis or be taking osteoporosis medicines. However, for those who continued in the study, in models adjusted for resident status, having cognitive impairment was related to lower adherence. Other studies have found less ${ }^{39}$ and more ${ }^{16,18}$ adherence among those who are cognitively impaired; and less ${ }^{10}$ and more ${ }^{9,14}$ adherence among those who are incontinent. One study found a significant relationship between depression and lower adherence, ${ }^{18}$ although this was not significant in adjusted analyses. However, comparisons across studies are complicated by the fact that not all controlled for similar characteristics or defined variables similarly. There is evidence, however, that residents at risk of fracture are more likely to be adherent. ${ }^{9,10}$ In light of conflicting resident-level findings and facility characteristics that suggest a need to target HP use, it may be that the best approach is one that is individualized: offer HPs to all residents who are at risk, and encourage their use in residents who are willing to wear them. The success of this effort in reference to adherence should be evident by twelve weeks time. ${ }^{40}$ This focus on individualized care is consistent with the importance of treating residents respectfully, which was significantly related to adherence until the fully adjusted model was run.

Despite being the only study to examine facility-level predictors of adherence to HPs in U.S. $\mathrm{NHs}$, this project has limitations. The most notable is that the HP was one-sided, raising concerns as to generalizability. Also, the project used a run-in period that results in higher adherence among those who remain in the study; similarly, research staff visited frequently to encourage adherence. Further, while a large number of facility- and resident-level characteristics were studied, not all were sufficiently powered for analyses. Still, findings that adherence is lower in NHs that have more Medicaid case-mix and African American residents and less training for certified nursing assistants, and in which staff are more burdened, can explain differences in adherence across studies and indicate settings in which special efforts are needed to encourage adherence with HPs to decrease fractures.

\section{Acknowledgments}

Funded by National Institutes of Health, National Institute on Aging grant R01 AG018461 and supported in part by the Lawrence J. and Anne Cable Rubenstein Charitable Foundation.

The authors thank Linda Ball, PhD, Washington University School of Medicine, St. Louis, MO, for her insights related to variable construction. They also thank the project coordinators and data collectors across all three clinical centers and the staff of the data coordinating center whose diligent efforts allowed this work to be conducted. 


\section{REFERENCES}

1. US Department of Health and Human Services. Hospital Inpatient Statistics 1996-1999. Agency for Health Care Policy and Research; Rockville, MD: 1999. AHCPR Publication 99-0034

2. Magaziner J, Fredman L, Hawkes W, et al. Changes in functional status attributable to hip fracture: a comparison of hip fracture patents to community-dwelling aged. Am J Epidemiol 2003;157:10231031. [PubMed: 12777366]

3. Magaziner J, Lydick E, Hawkes W, et al. Excess mortality attributable to hip fracture in white women aged 70 years and older. Am J Public Health 1997;87(10):1630-6. [PubMed: 9357344]

4. Zimmerman S, Girman CJ, Buie VC, et al. The prevalence of osteoporosis in nursing home residents. Osteoporos Int 1999;9:151-157. [PubMed: 10367043]

5. Ooms ME, Vlasman P, Lips P, et al. The incidence of hip fractures in independent and institutionalized elderly people. Osteoporos Int 1994;4:6-10. [PubMed: 8148574]

6. Rudman ID, Rudman D. High rate of fractures for men in nursing homes. Am J Phys Med Rehabil 1989;68:205. [PubMed: 2765213]

7. Parker MJ, Gillespie WJ, Gillespie LD. Hip protectors for preventing hip fractures in older people. Cochrane Database of Systematic Reviews. 2005;(3) DOI: 10.1002/14651858.CD001255.pub3. Art. No.: CD001255

8. BLINDED FOR REVIEW.

9. Cryer C, Knox A, Stevenson E. Factors associated with hip protector adherence among older people in residential care. Injury Prevention 2008;14:24-29. [PubMed: 18245311]

10. van Schoor NM, Deville WL, Bouter LM, et al. Acceptance and compliance with external hip protectors: a system review of the literature. Osteoporosis Int 2002;13:917-924.

11. Myers AH, Michelson JD, Van Natta M, et al. Prevention of hip fractures in the elderly: receptivity to protective garments. Arch Gerontol Geriatr 1995;21:179-189. [PubMed: 15374213]

12. Cameron ID, Quine S. External hip protectors: likely non-compliance among high risk elderly people living in the community. Arch Geront Geriatr 1994;19:273-281.

13. Kurrle SE, Cameron ID, Quine S. Predictors of adherence with the recommended use of hip protectors. Journal of Gerontology Medical Science 2004;59:958-961.

14. Warnke A, Meyer G, Bender R, et al. Predictors of adherence to the use of hip protectors in nursing home residents. JAGS 2004;52:340-345.

15. Lauritzen JB, Petersen MM, Lund B. Effect of external hip protectors on hip fractures. The Lancet 1993;34:11-13.

16. O'Halloran PD, Murray LJ, Cran GW, et al. The effect of type of hip protector and resident characteristics on adherence to use of hip protectors in nursing and residential homes - an exploratory study. Int J Nurs Studies 2005;42:387-397.

17. Burl JB, Centola J, Bonner A, et al. Hip protector compliance: a 13-month study on factors and cost in a long-term care facility. J Am Med Dir Assoc 2003;4:245-250. [PubMed: 12959651]

18. Honkanen LA, Monaghan N, Reid MC, et al. Can hip protector use in the nursing home be predicted? JAGS 2007;55:350-356.

19. Statehealthfacts.org.. United States: Total Number of Certified Nursing Facilities. 2006. (online). Available at: http://www.statehealthfacts.org/profileind.jsp?ind $=411 \&$ cat $=8 \& \mathrm{rgn}=1$. Accessed July 12,2008

20. Statehealthfacts.org.. United States: Certified Nursing Facility Beds. 2006. (online). Available at: http://www.statehealthfacts.org/profileind.jsp?ind=413\&cat=8\&rgn=1. Accessed July 12, 2008

21. Statehealthfacts.org.. United States: Total Number of Residents in Certified Nursing Facilities. 2006. (online). Available at: http://www.statehealthfacts.org/profileind.jsp?rgn=1\&cat=8\&ind=408. Accessed July 12, 2008

22. Zimmerman S, Gruber-Baldini AL, Hebel JR, et al. Nursing home characteristics related to Medicare costs for residents with and without dementia. Am J Alzheimers Dis Other Demen 2008;(1):57-65. [PubMed: 18276958] 
23. Zimmerman S, Gruber-Baldini AL, Hebel JR, et al. Nursing home facility risk factors for infection and hospitalization: importance of registered nurse turnover, administration, and social factors. J Am Geriatr Soc 2002;50(12):1987-95. [PubMed: 12473010]

24. BLINDED FOR REVIEW.

25. Sloane PD, Mitchell CM, Weisman G, et al. The therapeutic environment screening survey for nursing homes (TESS-NH): an observational instrument for assessing the physical environment of institutional settings for persons with dementia. Journal of Gerontology Social Science 2002;57:69_ 78.

26. Thal LJ, Grundman M, Golden R. Alzheimer's disease: a correlational analysis of the Blessed Information-Memory-Concentration Test and the Mini-Mental State Exam. Neurology 1986;36(2): 262-264. [PubMed: 3945395]

27. Lach H, Ball L, Birge S. Validation of a measure of fear of falling for nursing home residents. The Gerontologist 2002;421(1):171.

28. The National Heart, Lung, and Blood Growth and Health Study Research Group. Obesity and cardiovascular risk factors in black and white girls: the NHLBI growth and health study. Amer. Journal of Public Health 1992;82(12):1613-1620. [PubMed: 1456335]

29. Laird NM, Ware JH. Random-effects models for longitudinal data. Biometrics 1982;38(4):963-974. [PubMed: 7168798]

30. Mor V, Zinn J, Angelelli J, et al. Driven to tiers: socioeconomic and racial disparities in the quality of nursing home care. Milbank Q 2004;82(2):227-256. [PubMed: 15225329]

31. Cox H, Puffer S, Morton V, et al. Educating nursing home staff on fracture prevention: a cluster randomized trial. Age Ageing 2008;37(2):167-172. [PubMed: 18083724]

32. Jensen J, Lundin-Olsson L, Nyberg L, et al. Fall and injury prevention in older people living in residential care facilities. A cluster randomized trial. Ann Intern Med 2002;136(10):733-741. [PubMed: 12020141]

33. Zimmerman S, Sloane PD, Williams CS, et al. Dementia care and quality of life in assisted living and nursing homes. The Gerontologist 2005;45:133-146. [PubMed: 16230760]

34. Burgio LD, Fisher SE, Fairchild JK, et al. Quality of care in the nursing home: effects of staff assignment and work shift. The Gerontologist 2004;44:368-377. [PubMed: 15197291]

35. Stearns SC, D'Arcy LP. Staying the course: facility and professional retention among nursing assistants in nursing homes. G Gerontol B Psychol Sci Soc Sci 2008;63(3):113-121.

36. Hartig MT. Expert nursing assistant care activities. West J Nurs Res 1998;20(5):584-601. [PubMed: 9775740]

37. Spector WD, Selden TM, Cohen JW. The impact of ownership type on nursing home outcomes. Health Econ 1998;7:639-653. [PubMed: 9845257]

38. Rhoades JA, Potter DE, Krauss NA. Characteristics of nursing homes in 1996. Abstr Book Assoc Health Serv Res Meet 1997;14:303-4. Available at: http:/gateway.nlm.nih.gov/MeetingAbstracts/ ma?f=102233852.html.

39. Chan DK, Hillier G, Coorre M, et al. Effectiveness and acceptability of a newly designed hip protector: a pilot study. Archives of Gerontoloty and Geriatrics 2000;30:25-34.

40. Villar MT, Hill P, Inskip H, et al. Will elderly rest home residents wear hip protectors? Age Ageing 1998;27(2):195-198. [PubMed: 16296679] 

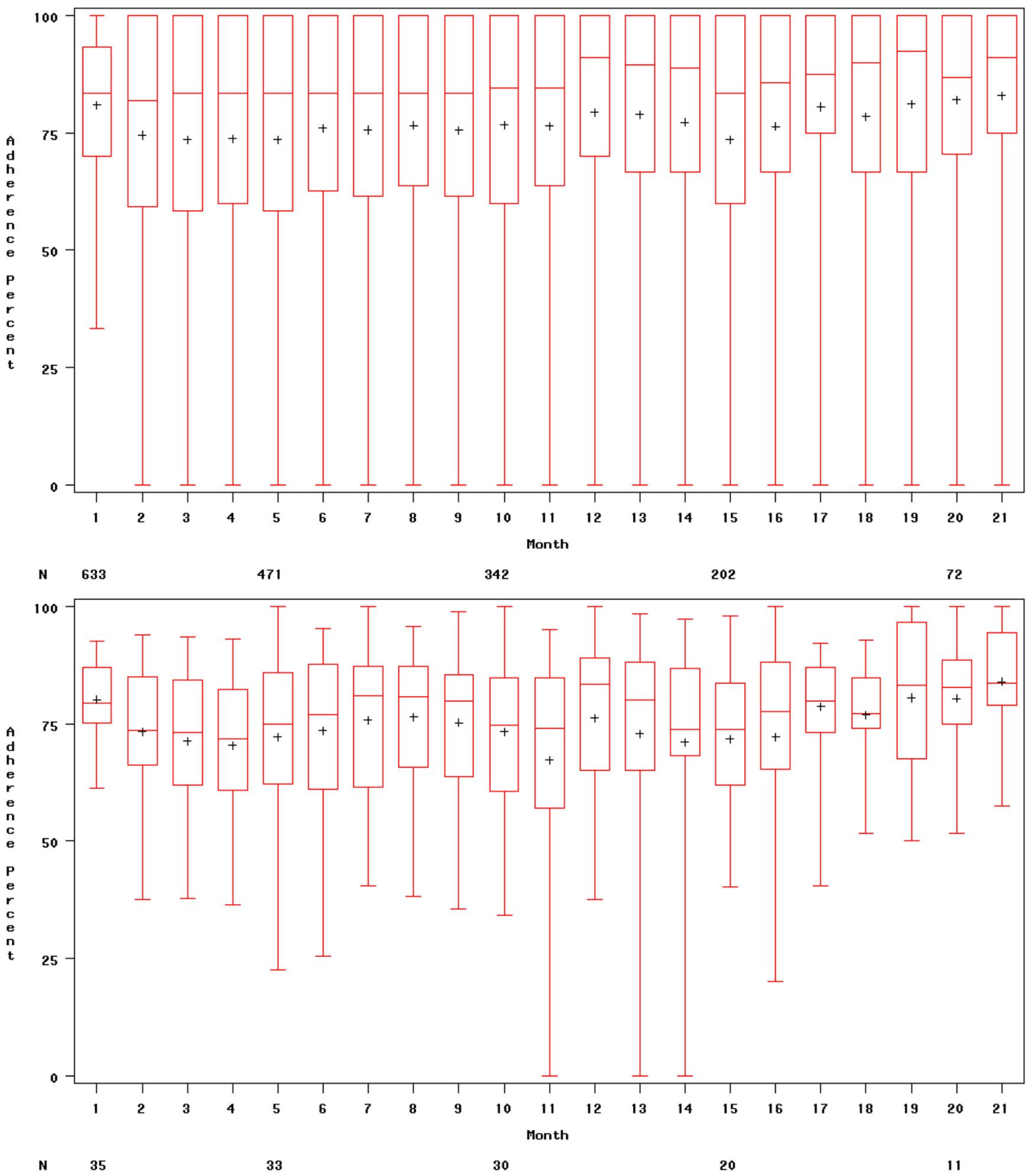

Figure 1.

Adherence by resident time in study (1a) and nursing home time in study (1b). The box indicates the interquartile range (25th-75th percentile); the plus sign inside of the interquartile range 
represents the mean; the line inside of the interquartile range represents the median; and the line extending from the box represents the extreme value. 


\section{Table 1}

Characteristics of Eligible Residents Who Refused to Participate, Did not Pass the Trial, and Dropped Out, Through Nine Months Post Facility Randomization ${ }^{a}$

\begin{tabular}{|c|c|c|c|c|}
\hline & \multirow[b]{3}{*}{$\begin{array}{c}\begin{array}{c}\text { Refused } \\
(\mathrm{N}=\mathbf{2 2 6 8})\end{array} \\
\text { Number }(\%) \\
\text { or Mean (SD) }\end{array}$} & \multicolumn{3}{|c|}{ Agreed to Participate $(\mathrm{N}=797)$} \\
\hline & & \multirow[b]{2}{*}{$\begin{array}{c}\text { Did Not } \\
\text { Pass Trial } \\
(\mathrm{N}=164) \\
\text { Number (\%) } \\
\text { or Mean (SD) }\end{array}$} & \multicolumn{2}{|c|}{ Passed Trial $(\mathrm{N}=633)$} \\
\hline & & & $\begin{array}{c}\text { Dropped Out } \\
(\mathrm{N}=236) \\
\text { Number }(\%) \\
\text { or Mean (SD) }\end{array}$ & $\begin{array}{c}\text { Did Not Drop } \\
\text { Out } \\
(\mathrm{N}=397) \\
\text { Number (\%) } \\
\text { or Mean (SD) }\end{array}$ \\
\hline \multicolumn{5}{|l|}{ Demographic Characteristics } \\
\hline Age (mean, SD) & $85.2(8.0)$ & $85.5(7.1)$ & $85.9(7.4)$ & $85.0(7.3)$ \\
\hline Gender, male & $492(21.7)$ & $32(19.5)$ & $52(22.0)$ & $70(17.6)$ \\
\hline Race, non-white & $123(11.6)$ & $22(13.4)$ & $40(17.0)$ & $51(12.9)$ \\
\hline Ethnicity, Hispanic & $11(0.8)$ & $1(0.6)$ & $3(1.3)$ & $3(0.8)$ \\
\hline Marital status, not married & & $140(88.6)$ & $205(87.6)$ & $339(85.6)$ \\
\hline \multicolumn{5}{|l|}{ Functional Status } \\
\hline $\begin{array}{l}\text { No cognitive impairment ( } \geq 12 \text { on the } \\
\text { Blessed Test) }\end{array}$ & & $38(23.5)$ & $43(18.3)$ & $70(17.7)$ \\
\hline Aggressive behavior scale & & $0.6(1.5)$ & $0.7(1.4)$ & $0.6(1.3)$ \\
\hline Do not wander & & $128(81.0)$ & $180(76.6)$ & $293(73.8)$ \\
\hline No depressive indicators & & $96(60.8)$ & $138(58.7)$ & $228(57.4)$ \\
\hline Continent of bladder & & $69(43.7)$ & $62(26.4)$ & $104(26.2)^{* * *}$ \\
\hline Continent of bowel & & $98(62.0)$ & $113(48.1)$ & $174(43.8)^{* * *}$ \\
\hline Independently mobile & & $66(41.8)$ & $60(25.5)$ & $120(30.2)^{* *}$ \\
\hline No falls in last six months & & $96(61.2)$ & $113(48.1)$ & $180(45.3)^{*}$ \\
\hline \multicolumn{5}{|l|}{ Health Status } \\
\hline History of hip fracture & & $10(6.4)$ & $14(6.0)$ & $29(7.3)$ \\
\hline Osteoporosis diagnosis & & $31(19.8)$ & $39(16.6)$ & $75(18.9)$ \\
\hline Alzheimer's disease, dementia diagnosis & & $89(56.7)$ & $158(67.2)$ & $274(69.0)^{*}$ \\
\hline Depression diagnosis & & $67(42.4)$ & $99(42.1)$ & $179(45.1)$ \\
\hline Number of medications & & $8.8(4.0)$ & $8.6(3.6)$ & $8.5(3.9)$ \\
\hline Taking medications for osteoporosis & & $11(7.0)$ & $27(11.5)$ & $58(14.7)^{*}$ \\
\hline Body mass index & & $25.0(4.6)$ & $24.2(4.4)$ & $24.8(4.6)$ \\
\hline
\end{tabular}

${ }^{a}$ Number missing: 4 (cognitive impairment); 7 (ethnicity, wandering, depressive indicators and depression diagnosis, incontinence, mobility); 8 (falls, osteoporosis diagnosis, Alzheimer's diagnosis, taking osteoporosis medications); 9 (marital status, history of hip fracture). Percents are column percents; using gender as an example, $21.7 \%$ of those who refused were male; $19.5 \%$ of those who did not pass the trial were male, $22.0 \%$ of those who dropped out were male, and $17.6 \%$ of those who did not drop out were male.

p $<.05$;

$\mathrm{p}<.01 ;$

* $\mathrm{p}<0.001$ for comparisons across all groups. 
Table 2

Multivariate Relationship of Facility Characteristics to Adherence ${ }^{a}$

\begin{tabular}{|c|c|c|c|}
\hline & Estimate & SE & P-value \\
\hline \multicolumn{4}{|l|}{ Demographics Characteristics ( $\mathrm{N}=6522$ observations) } \\
\hline Bedsize (per every 10 beds) & 0.20 & 0.04 & $<0.01$ \\
\hline Proprietary status, non-profit & 5.65 & 1.53 & $<0.01$ \\
\hline Case mix, percent of residents on Medicaid & -0.17 & 0.02 & $<0.01$ \\
\hline Affiliation, not chain-affiliated & 5.80 & 1.43 & $<0.01$ \\
\hline \multicolumn{4}{|l|}{ Staffing ( $\mathrm{N}=4993$ observations) } \\
\hline Percent rotating workers & 0.36 & 0.08 & $<0.01$ \\
\hline Nurses, registered and licensed (RN, LPN), Staffing ratio & -4.01 & 1.55 & $<0.01$ \\
\hline Certified nursing assistants (CNA), Staffing ratio & -1.62 & 0.67 & 0.02 \\
\hline DON, experience in facility & 0.03 & 0.01 & $<0.01$ \\
\hline \multicolumn{4}{|l|}{ Policies and Procedures ( $\mathrm{N}=5700$ observations) } \\
\hline Organizational leadership, Administrator index & -1.17 & 0.33 & $<0.01$ \\
\hline Organizational leadership, DON index & -1.29 & 0.38 & $<0.01$ \\
\hline Administrative priorities, DON & & & $<0.01$ \\
\hline \multicolumn{4}{|l|}{ Resident treated respectfully (reference $=$ least important) } \\
\hline Somewhat important & 15.26 & 3.56 & $<0.01$ \\
\hline Most important & 15.05 & 3.11 & $<0.01$ \\
\hline In-service training last quarter, percent nonprofessionals attended & 0.19 & 0.04 & $<0.01$ \\
\hline \multicolumn{4}{|l|}{ Hip Protectors and Related Experience ( $\mathrm{N}=6003$ observations) } \\
\hline Percent of eligible residents enrolled in HIP PRO & -0.35 & 0.09 & $<0.01$ \\
\hline Previous research involvement, past year (reference $=$ both yes) & & & $<0.01$ \\
\hline Administrator yes, DON no & 0.52 & 3.36 & 0.88 \\
\hline Administrator no, DON yes & -13.74 & 3.35 & $<0.01$ \\
\hline Administrator and DON no & -3.10 & 2.32 & 0.18 \\
\hline \multicolumn{4}{|l|}{ Research Staff Ratings ( $\mathrm{N}=5781$ observations) } \\
\hline Environmental quality (SCU-EQS score) & 0.41 & 0.13 & $<0.01$ \\
\hline Staff commitment to protector use (RN) & 3.05 & 1.11 & $<0.01$ \\
\hline \multicolumn{4}{|l|}{ Quality of interaction between research and facility staff } \\
\hline Facility staff approachable and responsive & 3.27 & 1.23 & $<0.01$ \\
\hline Quality of care & 3.96 & 1.15 & $<0.01$ \\
\hline \multicolumn{4}{|c|}{$\begin{array}{l}\text { Combined Demographic, Staffing, Policies/Procedures, Hip Protectors/Experience, and Staff Ratings } \\
\text { (N=5496 observations) }\end{array}$} \\
\hline Case mix, percent of residents on Medicaid & -0.10 & 0.03 & $<0.01$ \\
\hline Affiliation, not chain-affiliated & 6.73 & 1.67 & $<0.01$ \\
\hline Percent rotating workers & 0.47 & 0.09 & $<0.01$ \\
\hline Organizational leadership, Administrator index & -1.15 & 0.32 & $<0.01$ \\
\hline Administrative priorities, DON & & & 0.05 \\
\hline
\end{tabular}




\begin{tabular}{|l|c|c|c|}
\hline & Estimate & SE & P-value \\
\hline Resident treated respectfully (reference = least important) & & & \\
\hline Somewhat important & 8.13 & 3.82 & 0.03 \\
\hline Most important & 7.44 & 3.21 & 0.02 \\
\hline In-service training last quarter, percent nonprofessionals attended & 0.17 & 0.03 & $<0.01$ \\
\hline Percent of eligible residents enrolled in HIP PRO & -0.40 & 0.08 & $<0.01$ \\
\hline
\end{tabular}

${ }^{a}$ Only those variables significantly associated with adherence in multivariate models are shown; variables that were significant in bivariate models but not in multivariate models were: demographic characteristics (years in operation and percent of residents on Medicare); staffing (DON staffing ratio, RN turnover ratio, and overall staffing ratio); policies and procedures (percent attendance of professionals at in-service training, and having a falls prevention program); hip protectors (administrator and DON positive perception of hip protectors); and research staff ratings (facility,

administrator, DON, and certified nursing assistant commitment to protector use, quality of interaction between research and facility staff, and general working environment). 
Table 3

Multivariate Relationship of Resident Characteristics to Adherence ${ }^{a}$

\begin{tabular}{|c|c|c|c|}
\hline Demographic Characteristics ( $N=6639$ observations) & Estimate & SE & P-value \\
\hline Race, non-white & -10.17 & 1.94 & $<0.01$ \\
\hline Marital status, married & 5.06 & 1.92 & $<0.01$ \\
\hline \multicolumn{4}{|l|}{ Functional Status ( $\mathrm{N}=6635$ observations) } \\
\hline Cognitive impairment ( $\geq 12$ on the Blessed Test) & -7.34 & 1.90 & $<0.01$ \\
\hline Wandering $($ reference $=$ none $)$ & & & $<0.01$ \\
\hline Less than daily & -3.87 & 2.10 & 0.07 \\
\hline Daily & 4.01 & 2.10 & 0.06 \\
\hline Depressed, sad, or anxious mood (reference $=$ no mood indicators) & & & 0.02 \\
\hline Indicators present, easily altered & 1.26 & 1.53 & 0.41 \\
\hline Indicators present, not easily altered & -4.89 & 2.12 & 0.02 \\
\hline Incontinent, bladder (reference = always continent) & & & 0.04 \\
\hline Sometimes incontinent & 5.07 & 2.04 & 0.01 \\
\hline Frequently or always incontinent & 1.62 & 2.24 & 0.47 \\
\hline Incontinent, bowel (reference $=$ always continent $)$ & & & 0.01 \\
\hline Sometimes incontinent & -2.07 & 2.08 & 0.32 \\
\hline Frequently or always incontinent & -6.30 & 2.09 & 0.01 \\
\hline Mobility (reference $=$ independent) & & & $<0.01$ \\
\hline Supervision or limited assistance & 0.13 & 1.94 & 0.95 \\
\hline Extensive assistance or total dependence & 4.90 & 5.24 & 0.35 \\
\hline Wheelchair & -7.08 & 1.61 & $<0.01$ \\
\hline Activity did not occur & -5.90 & 7.78 & 0.45 \\
\hline \multicolumn{4}{|l|}{ Health Status ( $\mathrm{N}=6651$ observations) } \\
\hline Osteoporosis diagnosis & 5.71 & 1.74 & $<0.01$ \\
\hline \multicolumn{4}{|c|}{ Combined Demographic, Functional and Health Status ( $\mathrm{N}=6618$ observations) } \\
\hline Race, non-white & -8.76 & 1.92 & $<0.01$ \\
\hline Cognitive impairment ( $\geq 12$ on the Blessed Test) & -6.63 & 1.87 & $<0.01$ \\
\hline Wandering $($ reference $=$ none $)$ & & & $<0.01$ \\
\hline Less than daily & -2.59 & 2.08 & 0.21 \\
\hline Daily & 5.09 & 2.08 & 0.01 \\
\hline Depressed, sad, or anxious mood (reference $=$ no mood indicators) & & & 0.02 \\
\hline Indicators present, easily altered & 0.17 & 1.52 & 0.91 \\
\hline Indicators present, not easily altered & -5.40 & 2.11 & 0.01 \\
\hline Incontinent, bladder (reference = always continent) & & & 0.02 \\
\hline Sometimes incontinent & 5.44 & 2.00 & $<0.01$ \\
\hline Frequently or always incontinent & 1.73 & 2.20 & 0.43 \\
\hline Incontinent, bowel (reference $=$ always continent) & & & 0.02 \\
\hline Sometimes incontinent & -2.64 & 2.05 & 0.20 \\
\hline
\end{tabular}




\begin{tabular}{|l|c|c|c|}
\hline Demographic Characteristics (N=6639 observations) & Estimate & SE & P-value \\
\hline Frequently or always incontinent & -5.94 & 2.06 & $<0.01$ \\
\hline Mobility (reference = independent) & & & $<0.01$ \\
\hline Supervision or limited assistance & -0.28 & 1.91 & 0.88 \\
\hline Extensive assistance or total dependence & 2.21 & 5.16 & 0.67 \\
\hline Wheelchair & -7.08 & 1.59 & $<0.01$ \\
\hline Activity did not occur & -4.74 & 7.65 & 0.54 \\
\hline Osteoporosis diagnosis & 4.78 & 1.67 & $<0.01$ \\
\hline
\end{tabular}

${ }^{a}$ Only those variables significantly associated with adherence in multivariate models are shown; variables that were significant in bivariate models but not in multivariate models were: health status (taking medications for osteoporosis). 
Table 4

Multivariate Relationship of Facility and Resident Characteristics to Adherence ( $=5489$ observations)

\begin{tabular}{|c|c|c|c|}
\hline & Estimate & SE & P-value \\
\hline \multicolumn{4}{|l|}{ Facility Characteristics } \\
\hline Case mix, percent of residents on Medicaid & -0.10 & 0.03 & $<0.01$ \\
\hline Affiliation, not chain-affiliated & 5.05 & 1.66 & $<0.01$ \\
\hline Percent rotating workers & 0.36 & 0.08 & $<0.01$ \\
\hline Organizational leadership, Administrator & -1.06 & 0.30 & $<0.01$ \\
\hline In-service training last quarter, percent nonprofessionals attended & 0.17 & 0.03 & $<0.01$ \\
\hline Percent of eligible residents enrolled in HIP PRO & -0.47 & 0.08 & $<0.01$ \\
\hline \multicolumn{4}{|l|}{ Resident Characteristics } \\
\hline Cognitive impairment ( $\geq 12$ on the Blessed Test) & -4.05 & 1.95 & 0.04 \\
\hline Wandering $($ reference $=$ none $)$ & & & $<0.01$ \\
\hline Less than daily & -3.39 & 2.19 & 0.12 \\
\hline Daily & 5.06 & 2.25 & 0.03 \\
\hline Depressed, sad, or anxious mood (reference $=$ no mood indicators) & & & $<0.01$ \\
\hline Indicators present, easily altered & 1.69 & 1.61 & 0.29 \\
\hline Indicators present, not easily altered & -6.90 & 2.17 & $<0.01$ \\
\hline Incontinent, bladder (reference $=$ always continent $)$ & & & 0.01 \\
\hline Sometimes incontinent & 1.78 & 1.99 & 0.08 \\
\hline Frequently or always incontinent & -3.14 & 1.80 & 0.37 \\
\hline Mobility (reference $=$ independent) & & & $<0.01$ \\
\hline Supervision or limited assistance & 1.43 & 2.03 & 0.48 \\
\hline Extensive assistance or total dependence & 3.24 & 5.27 & 0.54 \\
\hline Wheelchair & -4.69 & 1.66 & $<0.01$ \\
\hline Activity did not occur & -5.48 & 7.57 & 0.47 \\
\hline
\end{tabular}

